\title{
Configurações
}

Revista Ciências Sociais

\section{Intervenção em Centro Educativo: discursos a partir de dentro}

Intervention in Educational Center: discourses from within

Intervention dans des Centres éducatifs : des discours à l'intérieur

\section{Tânia Azevedo e Vera Duarte}

\section{(2) OpenEdition}

\section{Journals}

\section{Edição electrónica}

URL: http://journals.openedition.org/configuracoes/2447

DOI: $10.4000 /$ configuracoes. 2447

ISSN: 2182-7419

\section{Editora}

Centro de Investigação em Ciências Sociais

\section{Edição impressa}

Data de publição: 30 junho 2014

Paginação: 103-117

ISBN: 1646-5075

ISSN: 1646-5075

\section{Refêrencia eletrónica}

Tânia Azevedo e Vera Duarte, «Intervenção em Centro Educativo: discursos a partir de dentro »,

Configurações [Online], 13 | 2014, posto online no dia 23 abril 2015, consultado o 10 dezembro 2020.

URL : http://journals.openedition.org/configuracoes/2447 ; DOI : https://doi.org/10.4000/

configuracoes. 2447

\section{Este documento foi criado de forma automática no dia 10 dezembro 2020}

(c) CICS 


\title{
Intervenção em Centro Educativo: discursos a partir de dentro
}

\author{
Intervention in Educational Center: discourses from within \\ Intervention dans des Centres éducatifs : des discours à l'intérieur
}

\author{
Tânia Azevedo and Vera Duarte
}

\section{Introdução}

1 A intervenção com jovens delinquentes no sistema de justiça juvenil tem assumido um papel de destaque nas agendas política e de investigação da maioria dos países ocidentais (Duarte-Fonseca, 2005; Gomes et al., 2010; Carvalho, 2010).

2 No seu recorte político-legal, têm sido vários os desenvolvimentos nas políticas de proteção da infância e de intervenção relativamente à justiça e delinquência juvenis. A diferenciação entre "infância em perigo" e "infância perigosa" impôs esta necessidade de intervenções diversas (Carvalho, 2010), das quais resultou um grande número de instrumentos, diretrizes e acordos internacionais ${ }^{1}$ a serem implementados pelos Estadosmembros.

3 Em Portugal, a intervenção tutelar educativa é orientada por estes instrumentos internacionais e enquadrada pela Lei Tutelar Educativa (LTE) - Lei n.. $166 / 99$, de 14 de setembro. Em vigência desde 2001, é aplicada a jovens com idades compreendidas entre os 12 e os 16 anos que cometam atos qualificados na lei penal como crime, visando a sua educação para o direito e a interiorização de valores jurídicos e outros essenciais à vida em sociedade.

4 No campo da investigação e da prática, é principalmente a partir da década de 80 do século $\mathrm{XX}$, quando se rebate o mito de que nada funciona com os delinquentes juvenis, que se começa a consolidar uma literatura robusta - leia-se, baseada em dados rigorosos sobre prevenção e reabilitação de jovens delinquentes (Lipsey et al., 2010). São amplamente (re)conhecidos os diversos estudos que mudaram o pensamento sobre a 
intervenção com jovens infratores, que ficou conhecida como literatura do What Works, que emerge de estudos predominantemente quantitativos, de índole desenvolvimentista (e.g., Gendreau e Andrews, 1990; Moffi tt, 1993; Loeber e Farrington, 1998).

5 Estes estudos pretenderam identificar alguns princípios para uma intervenção eficaz, a saber: o desenho do programa e o protocolo de tratamento devem ser muito estruturados; devem estar focados no desenvolvimento de competências (interpessoais, académicas e de trabalho); devem usar modelos cognitivo-comportamentais e técnicas de aprendizagem social; e devem ser dirigidos à predição e avaliação do risco de reincidência, pela utilização de instrumentos estruturados ${ }^{2}$, capazes de discriminar variáveis associadas ao comportamento delinquente e tornar possível afirmar que tal comportamento é previsível de forma válida e precisa (Andrews e Bonta, 1994; Lipsey e Wilson, 1998; Andrews e Hoge, 2002; Andrews, Bonta \& Wormith, 2011).

6 Conhecer as circunstâncias pelas quais os/as jovens delinquentes reincidem é fundamental na hora de planificar e modificar o sistema de justiça juvenil, e foi neste contexto que a avaliação do risco e das necessidades criminogénicas ${ }^{3}$ se tornou um modelo/paradigma imprescindível, em uso no sistema de justiça juvenil da maior parte das sociedades ocidentais. A sua força explicativa tem sido rigorosamente comprovada nas dezenas de meta-análises realizadas sobre a avaliação dos efeitos dos programas na reincidência de jovens infratores (Lipsey et al., 2010).

7 Se internacionalmente o modelo da avaliação de risco se encontra bastante disseminado e avaliado, em Portugal o interesse e a sua aplicação é mais recente (Neves, 2009), mas em desenvolvimento (Pimentel et al., no prelo). A intervenção com jovens delinquentes no sistema de justiça juvenil português é protagonizada pela Direção-Geral de Reinserção e Serviços Prisionais (DGRSP). É uma intervenção voltada para a avaliação e gestão do risco e para a potenciação dos fatores de proteção. Fazem-no através, por um lado, da utilização de instrumentos de avaliação do risco, especificamente a YLS/CMI - Youth Level of Service/Case Managment Inventory (Hoge e Andrews, 2002), que começou a ser traduzida, adaptada e validada para Portugal em 2009 (Pimentel, 2011), e, por outro, pelo desenvolvimento de vários programas socioeducativos, terapêuticos e formativos.

O paradigma quantitativo e atuarial tem dominado a investigação e a intervenção neste domínio (Lipsey et al., 2010; Office of Juvenile Justice and Delinquency Prevention, EUA), secundarizando as implicações práticas dos resultados da investigação de índole mais qualitativa (Hubbard e Matthews, 2008). Continuam a ser poucos os estudos que tenham examinado o sistema de justiça (juvenil) e a intervenção que nele é desenvolvida, a partir dos pontos de vista daqueles/as que já o experienciaram (Butler, 2011).

Em Portugal, os poucos estudos qualitativos desenvolvidos têm-se focado, primordialmente, nas trajetórias de vida de jovens em cumprimento de medidas tutelares educativas (Carvalho, 2003; Seabra, 2005; Duarte et al., 2004; Duarte, 2012), nos centros educativos e suas dinâmicas (Neves, 2008), ou nas representações sociais dos jovens sobre a intervenção tutelar educativa (Manso, 2006). Assiste-se a uma lacuna bibliográfica no que se refere a estudos com ou sobre os/as profissionais que intervêm no sistema de justiça juvenil (e.g., nos tribunais, nos centros educativos, nas equipas de reinserção social). Nesta esteira, o estudo apresentado neste artigo, ao trazer as perceções que jovens internados e profissionais de Centro Educativo constroem sobre a intervenção tutelar educativa (Azevedo, 2013), poderá ser um contributo de relevo na discussão que se impõe. Ao revelar o interesse em entender como é que os/as atores/as sociais dão sentido às experiências quotidianas e como as construções sociais, culturais e profissionais 
interferem nas suas visões e "teorias", propõe-se passar para o nível dos significados e das representações.

Sabe-se que o processo através do qual os indivíduos formam as suas representações é extremamente complexo, estando em grande medida relacionado com a forma como os sujeitos interpretam e percecionam a realidade (Jodelet, 1988; Vala, 1997), com vista a posicionarem-se perante uma situação e agirem em relação a ela. Enquanto interpretações da realidade, as representações estão vinculadas a valores, noções e práticas individuais - dentro de um determinado contexto (histórico, cultural, social) que orientam as condutas no quotidiano.

11 Foi neste cruzamento com "a vida como é vivida, como é experienciada e como é contada" (Bruner, 1986) que se escreveu este artigo, que pretende contribuir para colmatar esta lacuna de conhecimento, ao estudar a intervenção em centro educativo a partir de dentro, dando voz às experiências e aos relatos de jovens internados e de profissionais de reinserção social. Este texto constitui um recorte de uma investigação qualitativa mais ampla sobre Institucionalização e Lei Tutelar Educativa, desenvolvida no âmbito de uma dissertação de mestrado, e trará para a discussão dos dados alguns dos principais resultados de um projeto de investigação sobre Delinquência Juvenil ${ }^{4}$, na qual as autoras participaram.

\section{Princípios da intervenção com jovens em cumprimento de medida tutelar educativa em Portugal}

12 O princípio da intervenção tutelar educativa, enquadrada legalmente pela LTE, não assenta na punição mas numa aprendizagem e interiorização de valores e normas sociais e do dever-ser jurídico (Torres, 2010), que a lei qualifica de "educação para o direito". Consoante as necessidades dessa educação que subsistam no momento de aplicação da medida, da gravidade do delito, do nível de maturidade do/a jovem e da situação sociofamiliar do/a mesmo/a, são aplicadas medidas tutelares que podem ser não institucionais/comunidade ou institucionais/internamento em Centro Educativo (art. 4. ${ }^{\circ}$ da LTE).

13 Compreender em que consiste e o que pressupõe a educação do/a jovem para o direito, no âmbito da intervenção tutelar educativa, e de que forma se implementam os processos educativos previstos, é um debate presente e pouco consensual. Por um lado, porque o texto da LTE é vago quanto ao significado da expressão "educar para o direito" (Neves, 2007), por outro lado, por causa da heterogeneidade de abordagens teóricas na compreensão dos processos educativos levados a cabo no contexto da aplicação da lei (Torres, 2010).

14 A intervenção que é protagonizada pela Direção-Geral de Reinserção e Serviços Prisionais (DGRSP) no âmbito do tutelar educativo assenta numa perspetiva desenvolvimentista da delinquência, como vimos anteriormente, acompanhando o que têm sido as discussões mais atuais da literatura sobre o que melhor funciona com jovens delinquentes no sistema de justiça juvenil.

15 Nesta esteira, a intervenção é pensada levando em consideração um modelo conceptual integrativo e de matriz relacional (Direção-Geral de Reinserção Social [DGRS], 2009). Integrativo, porque compreende conceções, técnicas, programas e procedimentos de vários modelos de intervenção (abordagens cognitivas, na sua vertente comportamental e 
desenvolvimentista, e abordagens sistémicas e ecológicas). Estas perspetivas encararam a delinquência de forma multifatorial e pressupõem uma intervenção global sobre o/a jovem, a família e o meio, implicando o desenvolvimento de um trabalho articulado com as várias instituições que atuam junto dos/as jovens e seu contexto. De matriz relacional, porque valoriza o papel do/a técnico/a com o/a jovem em cumprimento de medida e desenvolve um sistema de relações claramente diferente daquelas que pautaram o desenvolvimento desses/as jovens, o que se pede a estes profissionais, especificamente aos técnicos superiores e profissionais de reinserção social, é que desenvolvam competências que lhes possibilitem avaliar sem julgar, prever comportamentos, ser perseverantes e compreensivos - características que conferem à relação um valor positivo e facilitador do processo de mudança.

Neste sentido, a intervenção pressupõe ser: individualizada e planificada; ajustada ao nível de risco de reincidência e às necessidades identificadas, reforçando os fatores de proteção; promotora do envolvimento da família e da comunidade e do reforço dos vínculos do/a jovem às instâncias socializadoras; promotora da responsabilização do/a jovem e de uma mudança comportamental e atitudinal; capaz de avaliar o progresso do/a jovem nas áreas de intervenção definidas (DGRS, 2009). Estes princípios têm de estar espelhados no saber-fazer dos/as profissionais.

17 A intervenção em Centro Educativo é suportada por instrumentos próprios (e.g., projeto de intervenção educativa e regulamento interno), definidos à luz dos quadros legais em vigor. Segue um modelo progressivo e faseado ${ }^{5}$ e está estruturada em torno de programas educativos e terapêuticos ${ }^{6}$. Esta filosofia interventiva não deixa, contudo, de ser influenciada pelo facto de os centros educativos manterem a característica de "espaço educativo total" (Neves, 2008). "Espaço educativo", por cumprir os objetivos da LTE: "educar para o direito" e "garantir uma reinserção digna e responsável na vida em comunidade". "Total", porque apresenta as características da instituição total protagonizada por Goffman (1961: 41) "como um lugar de residência e trabalho em que um grande número de indivíduos colocados na mesma situação separados do mundo exterior durante um período relativamente longo, levam em conjunto uma vida de reclusão cujas modalidades são explicitamente e minuciosamente regulamentadas".

Esta característica faz com que as funções da instituição sejam percebidas, pelos seus, de forma diferente; ou seja, enquanto os educandos/as percecionam e sentem o internamento como uma sanção, os/as profissionais veem-no como uma possibilidade de recuperação (Garcia, 2002; Manso e Almeida, 2009).

\section{Método}

19 Este artigo apresenta e discute parte dos resultados de uma pesquisa de mestrado sobre representações que jovens a cumprir medida tutelar de internamento e profissionais que trabalham em Centro Educativo têm sobre as trajetórias de vida desses jovens e sobre a intervenção que é desenvolvida em Centro Educativo.

Neste texto, o foco será colocado neste segundo objetivo.

21 A opção metodológica seguiu os caminhos da investigação qualitativa. Desenvolveu-se um estudo de carácter assumidamente exploratório, por ser uma primeira aproximação a um tema pouco estudado em Portugal. Delimitada a um contexto específico, a pesquisa foi realizada num Centro Educativo do Norte do país ${ }^{7}$ e decorreu entre outubro de 2012 e 
outubro de 2013. Pela natureza do estudo, não se pressupõe a generalização dos resultados ou a representatividade da amostra, apesar de não se terem descurado as preocupações com a validade da investigação, ora pela aplicação e combinação de diferentes técnicas de investigação, ora no processo dialógico de confrontação com a teoria (Bogdan \& Bilken, 2010).

\section{Participantes}

A seleção da amostra/participantes do estudo baseou-se num conjunto de critérios previamente pensados que pudessem garantir uma amostra de variação máxima, a saber: género, tempos de cumprimento de medida e diversidade funcional.

Estes critérios foram reajustados aquando da entrada no terreno, para responder aos tempos da investigação e às dinâmicas e permissões da instituição onde decorreu o estudo. No caso dos jovens, não foi possível garantir a diversidade de género. $O$ número de participantes foi constrangido pelas rotinas institucionais. Deste reajustamento construiu-se uma amostra constituída por nove (9) jovens do sexo masculino, com diferentes tempos de cumprimento de medida (ver Quadro 1); e quatro (4) profissionais, três mulheres e um homem, de diferentes categorias profissionais (ver Quadro 2).

QUADRO 1. CARACTERIZAÇÃo dOS JOVENS PARTICIPANTES NA AMOSTRA

\begin{tabular}{|l|l|l|c|}
\hline $\begin{array}{l}\text { Nome } \\
\text { (fictício) }\end{array}$ & Idade & $\begin{array}{c}\text { Duração } \\
\text { da medida de internamento }\end{array}$ & $\begin{array}{c}\text { Período da medida já } \\
\text { cumprido }\end{array}$ \\
\hline Vasco & 16 anos & 24 meses & 12 meses \\
\hline Lourenço & 17 anos & 12 meses & 8 meses \\
\hline Vicente & 17 anos & 12 meses & 6 meses \\
\hline Sebastião & 18 anos & $\begin{array}{c}\text { Primeira Medida }-24 \text { meses } \\
\text { Segunda Medida }-18 \text { meses }\end{array}$ & 4 meses da segunda \\
\hline José & 18 anos & 12 meses & 4 meses \\
\hline Dinis & 16 anos & 20 meses & 10 meses \\
\hline Bernardo & 16 anos & 18 meses & 11 meses \\
\hline Duarte & 18 anos & 24 meses & 21 meses \\
\hline Henrique & 18 anos & 24 meses & 21 meses \\
\hline
\end{tabular}

Fonte: PROCESSOS TUTELARES DOS JOVENS EM CUMPRIMENTO DE MEDIDA DE INTERNAMENTO NO CENTRO EDUCATIVO EM ESTUDO, CONSULTADOS ENTRE OUTUBRO DE 2012 E OUTUBRO DE 2013.

QUADRO 2. CARACTERIZAÇÃO DOS/AS PROfISSIONAIS PARTICIPANTES NA AMOSTRA 


\begin{tabular}{|l|l|l|l|}
\hline $\begin{array}{c}\text { Nome } \\
\text { (fictício) }\end{array}$ & Idade & Habilitações literárias & $\begin{array}{c}\text { Categoria profissional } \\
\text { (sigla) }\end{array}$ \\
\hline Isabel & 50 anos & Licenciatura em Psicologia & $\begin{array}{l}\text { Elemento da Direção } \\
\text { (ED) }\end{array}$ \\
\hline Clara & 32 anos & $\begin{array}{l}\text { Licenciatura em Serviço } \\
\text { Social }\end{array}$ & Técnico Superior (TS) \\
\hline Filipe & 42 anos & Licenciatura em Sociologia & Técnico Superior \\
\hline Luísa & 30 anos & Licenciatura em Psicologia & $\begin{array}{l}\text { Técnica profissional } \\
\text { (TP) }\end{array}$ \\
\hline
\end{tabular}

Fonte: entrevistas realizadas aOS ProfissionaIs, entre março e maIO de 2013.

\section{Instrumento(s) de recolha e análise dos dados}

Para a recolha da informação foi utilizada a entrevista semiestruturada, como técnica principal (realizada entre março e maio de 2013), complementada com a consulta dos processos individuais dos jovens internados, através de uma grelha construída para o efeito, e com a análise do Projeto Educativo do Centro.

Utilizou-se um guião de entrevista flexível, orientado por tópicos. As entrevistas foram gravadas em áudio e foram realizadas no próprio local da pesquisa, numa sala cedida para o efeito. As entrevistas foram transcritas de forma literal e posteriormente codificadas e categorizadas, seguindo-se um conjunto de procedimentos que assentou essencialmente na análise de conteúdo (categorial e temática) das entrevistas. Foram operacionalizadas quatro grandes categorias: a trajetória de vida dos jovens antes do cumprimento da medida; o percurso dos jovens dentro do Centro Educativo; a intervenção tutelar educativa (representações sobre a LTE, funções e intervenção educativa em Centros Educativos); as expectativas futuras face aos jovens.

Este artigo irá focar-se apenas na dimensão da intervenção desenvolvida em centro educativo, que teve como subcategorias de análise os sistemas normativo e relacional.

\section{Considerações éticas}

Os princípios éticos assegurados traduziram-se na solicitação do consentimento informado dos sujeitos ou dos encarregados de educação dos menores, onde estavam plasmados os objetivos do estudo, o pedido para a gravação das entrevistas e a garantia de reserva de anonimato e de confidencialidade de todos os dados recolhidos. Além destes aspetos, foi assegurado que as informações recolhidas não seriam utilizadas para outros fins que não os da investigação. Neste artigo, de forma a garantir a privacidade e o anonimato dos/as participantes, os seus nomes reais foram substituídos por nomes fictícios. 


\section{Discursos sobre a intervenção em Centro Educativo}

Os significados emergentes dos discursos dos jovens e dos/as profissionais participantes no estudo sobre a intervenção em Centro Educativo mostram-nos pontos de convergência relativamente às funções do centro e à relevância atribuída ao técnico como fi gura de referência ao longo de todo o processo; mas também modos distintos de interpretar o mundo quando falam sobre a dimensão normativa da intervenção.

\subsection{Representações sobre o Centro Educativo: dimensão normativa da intervenção}

o Centro Educativo é visto, por jovens e profissionais, como uma instituição de controlo formal que visa responder às necessidades educativas dos/as jovens que cometeram atos ilícitos, sublinhando a sua importância na sua vida futura pelo facto de lhes proporcionarem uma formação escolar e profissional, a aquisição de hábitos e rotinas e a aprendizagem de competências, pessoais e sociais, associadas a valores sociomorais.

Para a maioria dos jovens, a escola, as oportunidades de realização de estágios no exterior do centro, as regras relacionadas com hábitos e rotinas (e.g., hora de deitar e acordar, hábitos de higiene, frequência das aulas) são apontados como os aspetos mais importantes no Centro Educativo. Como refere expressivamente Vicente, de 17 anos, o Centro Educativo "tira-nos [do meio no qual estavam inseridos], não fumamos, temos escola, temos regras a cumprir, temos horas para comer, hábitos e higiene". Para os/as profissionais, estas oportunidades irão contribuir para que os jovens adquiram, além das competências formativas, maior responsabilidade, autonomia, autoestima e um aumento dos vínculos sociais positivos. Para Isabel, elemento da direção, o centro educativo "garante-lhes [...] a frequência do ensino, dá-lhes a possibilidade de eles concluírem o 6.ำ ou o 9." ano e de terem uma formação tecnológica; dá-lhes acesso a programas de competências sociais e competências de vida diária".

31 Apesar de partilharem o mesmo ponto vista quanto às funções do Centro Educativo e à importância deste na integração social dos jovens, assiste-se a uma divergência de opiniões relativamente ao sistema normativo da instituição, expresso nos regulamentos próprios e nos projetos de intervenção educativa.

32 A maior parte dos jovens entrevistados diz que há regras com as quais não concorda, por não entender a sua importância na vida futura, considerando-as como o pior no Centro Educativo. Estes jovens destacam a rigidez dos movimentos ${ }^{8} \mathrm{e}$ a obrigatoriedade de pedir licença para tudo:

"Não podemos andar à vontade, não podemos andar um aqui outro aqui; temos que andar em fila, temos que pedir 'posso?'." (Bernardo, 16 anos)

“[...] Mudava muitas regras [...]. Para já, não se andava encostado à parede, não havia fase inicial, era toda a gente com os mesmos privilégios, podia-se falar, com modos, mas podia-se falar o que se quisesse, e aqui não se pode." (Lourenço, 17 anos)

"Andar encostado à parede, lá fora não cabe na cabeça de ninguém [...]. Aqui há regras que eu não sei para quê que isto dá para nossa vida [...]. Ter de pedir 'posso?' para tudo, deitar cedo, fazer chamadas em dias específi cos [...]. Isso lá fora para mim não vai servir pra nada..." (Sebastião, 18 anos) 
33 Já para os/as profissionais, este sistema normativo é crucial pela importância dada às rotinas, à criação de hábitos, ao treino de competências e à necessidade de consciencializar estes/as jovens para o cumprimento de normas.

Apesar de não ter ficado clara a tese de Garcia (2002), que defende posições dicotómicas na forma como educandos e educadores percecionam o Centro Educativo - para os jovens internados uma sanção, para os profissionais e dirigentes um organismo reabilitador da conduta e potenciador de mudança -, é incontestável a tensão existente em torno das visões sobre o sistema normativo.

Como já defendido em outras investigações realizadas em Portugal (Neves, 2007; Manso \& Almeida, 2009), parece haver um certo distanciamento entre a filosofia educativa subjacente ao sistema normativo e a perceção que os/as jovens têm dessa filosofia. Este desfasamento, que até poderia ser encarado como normal, levando em consideração que a dinâmica institucional se desenvolve em torno de duas mundovisões - a institucional e a dos/as jovens internados/ as - introduz dados na reflexão. Não será este desfasamento um procedimento de defesa da própria instituição face aos perigos potenciais no seu interior?

Será que há regras que não são propositadamente explicadas, para conservar a demarcação experiencial e estatutária entre agentes educativos e educandos/ as, e a estruturação do quotidiano em torno do permitido e do proibido? A este respeito, Neves (2008) argumenta que, no funcionamento quotidiano do Centro Educativo, as esferas educativa e relacional tendem a subsumir-se nesse processo de defesa institucional, que "habilita" os/as técnicos/as de uma capacidade de previsão e antecipação das situações. Esta perspetiva, ainda que muito arraigada ao conceito goffmaniano de instituição total (Goffman, 1961), é uma consequência da própria reflexividade organizacional. É importante perceber e questionar se uma preocupação excessiva com o cumprimento de normas institucionais e processuais se está a sobrepor ao objetivo da reeducação e da transformação do indivíduo.

\subsection{A dimensão relacional da intervenção}

É consensual entre os participantes deste estudo que a relação entre os/as técnicos/as e os/as jovens se revela um fator elementar no percurso institucional. o princípio da relação surge como um motor de mudança.

A maioria dos jovens entrevistados destaca que um dos fatores essenciais de todo o percurso de internamento é a relação interpessoal com os/as técnicos/as, sublinhando que a proximidade da relação contribui para o sucesso da intervenção, para as mudanças atingidas e para as competências adquiridas.

Para Henrique, de 18 anos, os técnicos "souberam-me respeitar, não entraram logo no meu espaço, não o invadiram [...]”. As tutorias ${ }^{9}$ são referenciadas também como algo importante na intervenção, apesar de, implicitamente, os/as jovens as considerarem como um meio de atingir privilégios. Para Lourenço, de 17 anos, “[...] a partir das tutorias é que fazem a minha análise, para ver se posso sair lá fora, ou se posso ir a casa [...]. E serve também para dar os relatórios a tribunal e assim, falarem comigo, como é que eu estou [...]". Ao demonstrarem as suas evoluções e bom comportamento, os/as jovens podem ser beneficiados nas avaliações. No entanto, afirmam reconhecer que se trata de um importante espaço de comunicação, reflexão e aprendizagem. Segundo Bernardo, de 
16 anos, "nas tutorias nós falamos da nossa vida, do passado, do que mudámos, do que falta mudar [...]".

Também os/as profissionais relevam o papel do/a técnico/a no percurso da execução da medida de internamento, considerando-o/a como uma referência importante para o/a jovem. Apesar de não existir um estilo educativo único que produza os melhores resultados, os/as técnicos/as entrevistados/as acreditam que o mais eficaz incide na simbiose entre a disciplina e o afeto. A este respeito, Filipe, técnico superior, diz que: "o grande erro em que se cai, aqui e noutros Centros, é a gente tentar intervir, ou trabalhar, ou lidar com estes miúdos num ponto de vista ou num patamar superior, de quem conhece e de quem sabe; e não pode ser assim, tem que ser ao contrário, [...] descer ao nível deles, e é isso que eu faço todos os dias até àquela linha, até à linha da disciplina, até à linha de 'daqui não pode ser". Esta ideia da disciplina é sublinhada também por Clara, técnica superior, quando diz que: "é a forma como tu atuas e levas a atuar no teu dia a dia, são as correções na hora, o 'pede desculpa', o 'pede por favor'; são as nossas práticas do quotidiano que aqui se tentam de facto incutir."

o processo de aprendizagem é, assim, facilitado pela dimensão afetivo-relacional, que é valorizada no contexto de intervenção, apesar de conjugada com uma postura firme e reguladora por parte dos agentes educativos. Ora, atingir este equilíbrio não parece ser fácil. Segundo Duarte e Joaquim (2012), há uma tendência dos/as técnicos/as para assumir atitudes mais normativas e disciplinares e, consequentemente, menos flexíveis na intervenção. Os/as técnicos/as com posturas mais assertivas apresentavam posicionamentos mais pedagógicos, menos disciplinares e mais flexíveis, evidenciando um esforço no sentido de adaptarem as estratégias de intervenção aos diferentes tipos de comportamento dos/as jovens, destacando a importância do reforço positivo como estratégia educativa e apresentando uma postura compreensiva face aos comportamentos.

Num sistema iminentemente normativo mas onde é valorizada a dimensão afetivorelacional, abre-se espaço para discutir as vantagens e inconvenientes de abordagens menos comportamentalistas e normativas, transformando as relação de força em relações de sentido, possuidoras de maior potencial ressocializador (Neves, 2011).

\section{Desafios à intervenção tutelar educativa: notas finais}

Quando os jovens em cumprimento de medida de internamento em Centro Educativo e profissionais da área da justiça falam sobre as suas experiências e dão a sua opinião sobre a intervenção educativa, uma variedade de discrepâncias interpretativas, de preocupações e de desafios torna-se aparente. Ficou clara a importância que jovens e profissionais atribuem à esfera educativa e relacional da intervenção, mas também o distanciamento que existe entre a filosofia educativa do sistema normativo e a perceção que os jovens têm dessa filosofia.

Sem ter o propósito de generalizar os dados, até pelas características da própria investigação desenvolvida, os discursos que aqui foram apresentados permitiram fazer algumas reflexões e inflexões mais alargadas sobre a intervenção no âmbito do tutelar educativo. 

- que está contemplada nos princípios da intervenção no âmbito do tutelar educativo que implica levar em consideração, por um lado, o impacto que o meio exerce sobre o/a jovem e, por outro, os ganhos obtidos com uma intervenção que contemple o meio no qual está inserido/a. Este modelo de intervenção pode ser fragilizado, por exemplo, pela reduzida intervenção que é feita junto da família. Segundo o relatório de Acompanhamento e Fiscalização dos Centros Educativos, "tudo se passa como se jovens e famílias fizessem parte de universos distintos que se tocaram antes da entrada no centro, e se tocarão depois, sem que haja interação entre a intervenção desenvolvida junto do jovem e a intervenção que deveria ser proposta à família" (CFCE, 2012: 35), no sentido de esta colaborar, responsabilizando-se pelo processo de reinserção social do/a jovem.

46

outra situação que pode igualmente fragilizar este modelo de intervenção sistémico é a quase inexistência de estruturas de continuidade (e.g., casas de autonomia) após a cessação da medida de internamento (Gomes et al., 2010). Terminada a medida, extinguese a responsabilidade do Centro Educativo (e do próprio sistema judicial) sobre o/a jovem, que passa de uma vigilância permanente e de um cenário "artificial" para um meio exterior, não raras vezes desestruturado e potenciador de situações de reincidência. A medida de internamento, como meio para atingir as finalidades da Lei Tutelar Educativa "educar para o direito" e "garantir uma reinserção digna e responsável na vida em comunidade" -, parece encerrar em si alguma contradição. Como podemos educar e preparar estes/as jovens para valores socialmente partilhados e para os desafios que irão encontrar na comunidade, a partir unicamente do contexto relacional do Centro Educativo (Manso e Almeida, 2009)? Possivelmente, a resposta a esta questão pode ajudar a perceber o porquê da discrepância percetiva, entre educandos/as e educadores/as, sobre as expectativas existentes após a saída do jovem do Centro Educativo. Os/as jovens não perspetivam quaisquer dificuldades na concretização do plano delineado: "Que dificuldade? Não vejo dificuldade nenhuma" (Lourenço, 17 anos). Por outro lado, os/as profissionais reconhecem que a integração social destes/as jovens não será isenta de obstáculos que podem colocar em causa a manutenção das aprendizagens adquiridas em Centro Educativo. Para Filipe, técnico superior, “[...] a maioria deles, senão todos e todas, saem daqui e voltam outra vez ao meio natural deles. E de facto, aí no sitio onde vivem, os valores não são os mesmos, por muito que a gente queira dourar a coisa". Como referem Duarte et al. (2004: 146), "tudo indica que 'lá fora' os problemas se mantêm e as referências identitárias passam a ser diferentes das do Centro". 2012), principalmente através da formação e dos estágios de índole profissional que permitem ao/à jovem a experiência de um conjunto de vivências em contexto real, esta situação parece não ser sufi ciente para conter e reduzir as taxas de reincidência que, segundo o último estudo (publicado) realizado em Portugal (Pimentel, Lagoa e Cóias, 2012), relativo aos/às jovens que terminaram medidas de internamento em 2009, 48,3\% reincidiram - assumido o somatório das taxas de reincidência e de indícios de reincidência -, sendo que destes/as $28,1 \%$ tiveram já decisão em sede de julgamento. Perceber os contornos da reincidência é importante, mas compreender os matizes da integração surge como um desafio ainda maior (Carneiro et al., 2011-2013).

Assim, em jeito de conclusão, é preciso garantir que uma preocupação excessiva com o cumprimento do sistema normativo não deturpe o verdadeiro objetivo da reeducação. É preciso assegurar que a intervenção desenvolvida não transforme a educação para o 
direito a pouco mais do que a interiorização de normas regulamentares de funcionamento interno (Neves, 2011). É fundamental compreender as consequências da "artificialidade educativa" dos centros nas trajetórias de reincidência e/ou integração social e garantir que esta clivagem de contexto (vida de centro/vida cá fora) não retire valor ao processo educativo.

É imperativo que se desenvolvam e integrem reflexões que combinem critérios de diferença (classe, género, etnia, orientação sexual), fundamentais no entendimento da intervenção e das diferentes interpretações construídas em torno dela. Reflexões que abrem perspetivas, na certeza de que muitas outras ficam por explorar.

\section{BIBLIOGRAPHY}

ANDREWS, Don \& BONTA, James (1994), The Psychology of Criminal Conduct. Cincinnati: Anderson Publishing.

ANDREWS, Don; BONTA, James \& WORMITH, Stephen (2011), “The Risk-Need-Responsivity (RNR) Model. Does adding the good lives model contribute to effective crime prevention?", Criminal Justice and Behavior, 38, 7: 735-755.

AZEVEDO, Tânia (2013), Institucionalização e Lei Tutelar Educativa: As representações de jovens, profissionais e direção de um Centro Educativo [Dissertação de Mestrado]. Braga: Universidade do Minho.

BOGDAN, Robert \& BILKEN, Sari (2010), Investigação qualitativa em Educação. Porto: Porto Editora. BRUNER, Edward (1986), "Experience and its expressions”, in Edward Bruner e Victor Turner (eds.), The Anthropology of Experience. Chicago: Illinois University Press, pp. 3-30.

BUTLER, Frank (2011), “Rush to judgment: Prisoners' views of juvenile justice”, Western Criminology Review 12(3): 106-119.

CARVALHO, Maria João Leote (2003), Entre as malhas do desvio. Oeiras: Celta Editora.

CARVALHO, Maria João Leote (2010), Do outro lado da cidade. Crianças, socialização e delinquência em bairros de realojamento. [Tese de Doutoramento em Sociologia]. Lisboa: Universidade Nova de Lisboa.

CFCE (2012), Relatório da Comissão de Acompanhamento e Fiscalização de Centros Educativos 2012. Lisboa: Ministério da Justiça.

DGRS (2009), Guião da intervenção tutelar educativa. Meio institucional. Lisboa: Ministério da Justiça. DUARTE-FONSECA, António (2005), Internamento de menores delinquentes. A lei portuguesa e os seus modelos: um século de tensão entre protecção e repressão, educação e punição. Coimbra: Coimbra Editora.

DUARTE, Ana Maria; BRANDÃO, Ana Maria; SILVA, Susana (2004), Violência juvenil - Histórias e percursos. Porto: Fundação da Juventude.

DUARTE, Vera (2012), Discursos e percursos na delinquência juvenil feminina. Famalicão: Edições Húmus. 
DUARTE, Vera \& JOAQUIM, Henrique (2012, não publicado), Realização de um estudo sobre o conteúdo das reuniões e passagens de turno nos Centros Educativos sob gestão partilhada da União Meridianos Portugal. Lisboa: CEPCEP/UCP.

GARCIA, Ana (2002), "Instituição total (Goffman) - Uma reflexão a propósito de Centros Educativos", Gestin, volume 1: 29-38.

GENDREAU, Don \& ANDREWS, Don (1990), “Tertiary prevention: What the meta-analisys of the offender treatment literature tells us about what works", Canadian Journal of Criminolgy, 32: 173-184.

GOFFMAN, Erving (1961), Manicômios, prisões e conventos. São Paulo: Perspectiva.

GOMES, Conceição (org.); FERNANDA, Paulo; PORTUGAL, Sílvia; SOARES, Carla; TRINCÃO, Catarina; SOUSA, Fátima; ALDEIA, João \& REIS, José (2010), Entre a lei e a prática. Subsídios para uma Reforma da Lei Tutelar Educativa. Coimbra: OPJ - CES.

HOGE, Robert \& ANDREWS, Don (2002), Youth Level of Service/Case Management Inventory: User's manual. Toronto, Canada: Multi Health Services.

HUBBARD, Dana \& MATTHEWS, Betsy (2008), "Reconciling the differences between the "Gender Responsive' and the 'What-Works' Literatures to Improve Services for Girls”, Crime \& Delinquency, 54 (2): 225-258.

JODELET, Denise (1988), “La representación social: fenómenos, concepto y teoría”, in Serge Moscovici, Psicología Social II - Pensamiento y vida social Psicología social e problemas sociales. Barcelona: Ediciones Paidós Ibérica, pp. 469-494.

LIPSEY, Mark \& WILSON, David (2001), Practical Meta-Analysis. California: Sage Publications.

LIPSEY, Mark; HOWELL, James; KELLY, Marion; CHAPMANN, Gabrielle \& CARVER, Darin (2010), Improving the Effectiveness of Juvenile Justice Programs. Center for Juvenile Justice Reform, Georgetown University [online] disponível em: http://cjjr.georgetown.edu/pdfs/ebp/ ebppaper.pdf [consultado em: 05/09/2014].

MANSO, Ana \& ALMEIDA, Ana Tomás de (2009), "Um discurso a duas vozes: potencialidades de um estudo interpretativo sobre lei e institucionalização", Psicologia: Refl exão Crítica, 22, 3: 455-465.

MANSO, Ana (2006), Educação para o Direito: Representações sociais de jovens institucionalizados em Centro Educativo. [Dissertação de Mestrado]. Braga: Universidade do Minho.

MOFFITT, Terrie (1993), “Adolescence-limited and life course-persistent antisocial behavior: a development taxonomy”, Psychological Review, volume 100 (4): 674-701.

NEVES, Ana (2009), Reincidência em comportamentos criminais e violentos: Caracterização e avaliação do risco. [Tese de Doutoramento em Psicologia]. Braga: Universidade do Minho.

NEVES, Tiago (2007), “A defesa institucional numa instituição total: o caso de um centro de internamento de menores delinquentes", Análise Social, volume 185: 1021-1039.

NEVES, Tiago (2008), Entre educativo e penitenciário: Etnografia de um centro de internamento de menores delinquentes. Porto: Edições Afrontamento.

NEVES, Tiago (2011), "Educação em Centro Educativo: Um lugar para a mediação", in Jorge Barreto Xavier (coord.), Arte e Delinquência. Lisboa: Fundação Calouste Gulbenkian: 107-118. OJJDP, Offi ce of Juvenile Justice and Delinquency Prevention. http://www.ojjdp.gov/ . PIMENTEL, Alberto (2011), “Avaliação do percurso dos jovens após a cessação de medidas tutelares educativas: Follow-up 2006-2008”, Ousar Integrar, 9: 71-81. 
PIMENTEL, Alberto; LAGOA, Teresa; CÓIAS, João (2012), “Avaliação do percurso dos jovens após a cessação de medidas tutelares educativas: Follow-up 2009”, Ousar Integrar, volume 12: 79-88.

PIMENTEL, Alberto; QUINTAS, Jorge; FONSECA, E. \& SERRA, A. (no prelo), “A avaliação do risco/ necessidades criminógenas de delinquentes juvenis: Dados normativos da adaptação portuguesa do Youth Level Service / Case Management Inventory (YLS/CMI) e dados preliminares de validade preditiva". Ousar Integrar, Revista de Reinserção Social e Prova.

TORRES, Raquel (2010), “Que Educação para o direito? Da Lei Tutelar Educativa à intervenção educativa com delinquentes juvenis", Ousar Integrar, Revista de reinserção social e prova, volume 7: 35-48.

\section{NOTES}

1. E.g., Convenção Internacional sobre os Direitos da Criança (1989); Regras Mínimas das Nações Unidas para a Administração da Justiça Juvenil (1985) - Regras de Beijing; Diretrizes das Nações Unidas para a Prevenção da Delinquência Juvenil (1990) - Princípios de Riade; Regras das Nações Unidas para a Proteção de Jovens Privados de Liberdade (1990) - Regras de Havana, Regras Mínimas das Nações Unidas para a Elaboração de Medidas não Privativas de Liberdade (1990) Regras de Tóquio.

2. Exemplo de alguns dos principais instrumentos de avaliação do risco, aplicados a jovens: SAVRY - Structured Assessment of Violence Risk in Youth; YLS/ CMI - Youth Level of Service/ Case Management Inventory; e PCL: YV - Psychopathy Checklist: Youth Version.

3. Um dos modelos mais populares é o modelo proposto por Andrews e Bonta (1994), também conhecido por Central Eight, que organiza os fatores de risco dividindo-os em três níveis de importância: os big four, os moderate four e os fatores de risco menores.

4. Projeto Delinquência Juvenil: Da ação à prevenção, coordenado pelo CEPCEP, da Universidade Católica Portuguesa, Lisboa (Coord. Científica: Roberto Carneiro) e financiado pela União Meridianos, Portugal. Foi executado entre 2011 e 2013 e dele resultaram três relatórios técnicos, não publicados. Um sobre os Conteúdos das reuniões e passagens de turno nos Centros Educativos sob gestão partilhada da União; um segundo sobre Retratos da prevenção da delinquência juvenil em Portugal; e o terceiro sobre os Impactos do projeto educativo da União Meridianos nas trajetórias de vida de jovens que cumpriram medida tutelar de internamento.

5. A intervenção educativa é progressiva e faseada porque pretende que o/a jovem atinja determinados objetivos e metas ao longo do internamento. O modelo está dividido em quatro fases: I - Avaliação Inicial; II - Desenvolvimento e Evolução; III - Consolidação; IV - Finalista/ Autonomia. $\mathrm{O} / \mathrm{a}$ jovem só passa à fase seguinte quando atinge os objetivos da fase anterior.

6. Atividades socioeducativas de carácter lúdico-desportivo e/ou de educação para a saúde; Programas terapêuticos e de satisfação das necessidades educativas associadas ao comportamento delinquente, como são exemplo os programas de treino de competências pessoais e sociais (GPS - "Gerar Percursos Sociais"); Psicoterapia individual e em grupo; Tutorias; Programas de formação escolar e profissional.

7. O Centro Educativo onde decorreu o estudo foi selecionado por questões de disponibilidade e proximidade geográfica. À data da investigação, existiam em Portugal oito Centros Educativos, dois dos quais sob a gestão partilhada da União Meridianos, Portugal.

8. Deslocações dos jovens em grupo nas instalações do Centro Educativo.

9. Espaços onde os jovens são acompanhados por um técnico superior - nomeado como tutor que o aconselha ao longo da medida, avaliando o seu comportamento e dando feedback com base no comportamento do jovem e no seu desempenho das atividades ao longo do dia. 


\section{ABSTRACTS}

Este artigo pretende refletir sobre a intervenção com jovens delinquentes no sistema de justiça juvenil, a partir das perceções de jovens a cumprir medida de internamento e dos/as profissionais que trabalham em Centro Educativo. Tendo por base dados empíricos obtidos a partir de uma investigação qualitativa realizada num Centro Educativo do país, os resultados mostram a importância que jovens e profissionais atribuem à esfera educativa e relacional da intervenção e o distanciamento entre a filosofia educativa do sistema normativo e a perceção que os/as jovens têm dessa fi losofia.

This paper aims to reflect about the intervention with young offenders within the juvenile justice system from the scope of the perceptions of young people placed in custody and the professionals working in an Education Centre. Based on empirical data collected from a qualitative research carried out on a Portuguese Education Centre, the results reveal the importance that young people and professionals attach to the educational and relational sphere of intervention, as well as the gap that exists between the educational philosophy of the normative system and the perception that young people have concerning that philosophy.

Cet article vise à réfléchir sur l'intervention avec des jeunes délinquants dans le système de justice des mineurs, à partir des perceptions des jeunes en internement et des professionnels qui travaillent dans des Centres éducatifs. Ayant pour base des données empiriques obtenues à partir d'une recherche qualitative menée dans un Centre éducatif du pays, les résultats dénotent l'importance que les jeunes et les professionnels attribuent à la sphère éducative et relationnelle de l'intervention, ainsi que le détachement qui existe entre la philosophie éducative du système normatif et la perception que les jeunes ont de cette philosophie.

\section{INDEX}

Mots-clés: Perceptions, intervention éducative tutélaire, Centre éducatif, recherche qualitative Palavras-chave: Perceções, intervenção tutelar educativa, Centro Educativo, investigação qualitativa

Keywords: tutelary educational intervention, Educational Centre, qualitative research

\section{AUTHORS}

TÂNIA AZEVEDO

ISMAI

taniazevedo@hotmail.com 


\section{VERA DUARTE}

Centro de Investigação em Ciências Sociais da Universidade do Minho e Unidade de Investigação em Criminologia e Ciências do Comportamento do Instituto Universitário da Maia. Endereço de correspondência: Av. Carlos Oliveira Campos - Castelo da Maia, 4475-690 Maia, Portugal vduarte@docentes.ismai.pt 